\title{
The Etnopoetic Constants the Heroic Epic of the Mongolian Peoples: The Issue of Identifying and Cataloguing
}

\section{Evdokia Erendjenovna Khabunova}

Kalmyk State University, Republic of Kalmykia, 358000, Elista, Pushkina Street, 11

\author{
Doi:10.5901/mjss.2015.v6n4s2p475
}

\section{Abstract}

\begin{abstract}
Lead: The urgent character of this investigation is the fact that it offers new approaches to the revealing and systematization of the ethnopoetical constants of the epic of Mongol nations which appear in an epic text of different levels. The work is based upon the theory of "ethnopoetical constants" by V. M. Gatsak. This theory allows to consider epic elements of different value in one analytical field as well as a wide range of "words in their stable expressions and connections" which have both the formulaicity and "mobility of the outlines". Revealing and systematization of the poetical and stylistic means that have differences in constancy in the epic of the Mongol nations both in general Mongol and local traditions, in national versions (Buryat, Kalmyck, Mongol, Xinjiang-Oirat), gives the opportunity to recreate the nature of the modelling of the inner connections and deep links of the separate narrative constructions of the heroic epic text, to define the basis of the existing stereotypes of the nomads' poetic thinking, to trace the character of formation of poetic images, symbols, concepts and categories.
\end{abstract}

Keywords: epic, Mongol nations, ethnopoetical constants, form levels, subject classification.

The study of the constant organisation of the epic text was initiated by V.M. Gatsak, who was the founder of a range of branches of the experimental folkloristic, creator of the ethnopoetical constants theory, main provisions of which were represented in his works and speeches of the scientific forums. Gatsak V. M. pointed out that "the ethnopoetical constants can appear on different levels, they have formulaicity but more often the constants have mobility of the outlines becoming stylistic and narrative coordinates of the pictured folklore world in the text (inherited) incarnation: verbal, musical (vocal and instrumental), actional (for, example customs), subject etc." [1].

The notion of "poetic constant" means, first of all, formulaicity. The essence of the "formula" was first defined by M. Perry, who found three criteria of its revealing in a text: notional completeness, presence of stereotypy and frequency in the tradition [2]. This notion was later improved and broadened by his student Albert Lord, who add to the formula new qualities, quite obvious, but not mentioned by the other investigators: "the expression of the given essential idea, i.e. the main sense", which is used in one and the same metric conditions within the "symbolic grammar" [3]. Such an approach to the understanding of the formula helps in defining the set of models, which are varied by the talented narrators while creating of performing of the epic text and "way of building metric verses and hemistiches by means of formulae and formula expressions and creating of the songs with the help of themes" [4]. Moreover, when revealing the formulae there appear difficulties in the epic text which are connected to the definition of the beginning and the end of the formulae. This was noticed by G. M. Foully, one of the critics of the Perry-Lord formula concept [5].

Despite the fact that the concept of the formula as the poetic an stylistic constant in the form of cliché, which fixes and generalizes different components of the poetic narration, has fixed in the folkloristic, there appear questions as the material accumulates, which need more profound study of the process of the epic text construction and revealing the role of the stereotype models in this process.

The theory of poetic constants by V. M. Gatsak allows to consider epic elements of different value i one analytical field as well as a wide range of "words in their stable expressions and connections" which have both the formulaicity and "mobility of the outlines". This opportunity was used while revealing and systematising of the constant fond of the heroic epic "Dzhangar". This opens new prospects for recreating the nature of the epic poetic stylistic system modelling, defining the basis of the existing stereotypes of the nomads' poetic thinking, to trace the character of formation of poetic images, symbols, concepts and categories [6].

The study of the epic constant fond of the Mongol nations and with the help of it - the revealing of the nature of the inner connections and deep links of the separate narrative constructions and elements which are constant in all the local traditions, allows us to understand the mechanism of the creation of the single epic, epic commonness which is preserved in different national versions despite the territorial disunity of their creators - the nations which are relative to the Mongols: 
Russian Buryats and Kalmycks, sovereign Mongols, Xinjiang Oirats and inner Mongols of China.

It is reasonable to study the textures of the homogeneous phenomena of the epic of the Mongol nations more profound, select and study poetic and stylistic means which are different in constancy in the general Mongol and local traditions, in national versions, in order to recreate the picture of formation of the epic works central core.

Ethnopoetical constants which are the ideological-artistic basis for the oral tradition of the Mongol nations, speak for the long-term process of the spiritual and practical exploration of the world performed by a human, by the endless resource of his poetic thinking, rich poetic and stylistic means for the art and by the keeper of the generations' memory. They open the way to the understanding of the artistic phenomenon of the nomads who has created famous epic works such as "Dhangar", "Geser", "Khan kharanguy", "DayniKurul", "Bum Erdeni" etc. They probably will help to recreate the traditional technique of the plot modelling, poetic-stylistic system by both the investigators and modern epic performers. The constant fond is important not only for the definition of the bases for the existing stereotypes of the nomads' poetic thinking, revealing of the character of formation of the poetic images, symbols and concepts, but also for the preservation of the cultural heritage, cultural originality of the Mongol nations and the richest accumulation of human knowledge. Poetic formulae that differ in constancy, allow to learn how the "national memory" can absorb the necessary out of the variety of the "heritage fond" and what is its aim when getting into the folklore art. Poetic constants help to trace the excessive things, what are the ideas of the narrator, singer by their poetic constants, what is behind the frequency and constancy of the poetic formulae.

Ethnopoetic constants which are gathered and systematized in one place can recreate the nature of the modelling of the poetic ad stylistic system of the folklore works, define the basis of the current stereotypes of the nomads' poetic thinking, nature of formation of the poetic images, symbols, concepts and categories.

The problem of systematization of the richest folklore material is of urgent nature, there appear new aspects of the scientific thinking of the folklore genres peculiarities. Poetic and stylistic peculiarities of the oral folk arts, separate ethnic and local traditions are not the exceptions. One of the instruments of the investigations in this sphere can be additional sources, in particular, the edition in the form of "Fond", which combines poetic and stylistic means, different in constancy in the folklore works (in general Mongol tradition, in national versions).

In the process of structuring of the fond of the ethnopoetical constants the experience of study of the motivational, thematic and formula organisation of the folklore works of both turco-mongolian and other nations will be taken into account [7]. The systematization of the stock of the typical places of the epic of the Siberian nations who speak Mongolian and Turkic was the significant help in the developing of the methodological issues. This was undertaken by Kuzmina E. N. in "Guide for the typical places of the heroic epic of Siberian nations" [8].

In order to reveal the constant fond we took the poetic-stylistic unit which has the constant and self-dependence, as the basic unit. This can be a large poetic description (macro-constant), for example, praise of the khan palace which is an integral part of the phenomenon of more significant categorical level (epic world) and stable expression (microconstant), tightened by the key word which characterises certain segment, peculiarity of the described event, phenomenon or object (in this case - khan palace) (garh talk biyin' gajgshilyaryonglsn, orh talk biyin' usnshilyaryonglsn [9] - the side of the rise [of the sun] is decorated with the mosaic glass, the side of the set [of the sun] is decorated with the crystal).

The role of the ethnopoetic constants can be observed in the combination of different parts of the folklore text, provision of their formal and semantic links. This allows us to speak about the modelling, structure-forming function of constants which acquire symbolic implementation in the text.

Previously, the descriptions are taken from the whole epic narration. These descriptions have different constants in different texts (versions) within one epic tradition, for example, in the Kalmyck epic "Dzhangar" (in three main versions: Maloderbetovsky, Bagatsokhurovsky and EelyanOvla and in other chapters of separate performers, if necessary). These macro-constants in the epic text can be found a lot of times in different variants, but only few of them show the stableness of expressions, which are based on one and the same support word. These macro-constants will build the main fond of the poetic constants of the Mongol nations' epic.

This scheme can be applied to the selection of the poetic constants out of the other epics of the Mongol (and other) nations. This multi-level approach allows to systematize ethnopoetic macro- and micro-constants of the epic of the Mongol nations, basing on the principle of the subject classification:

I. Epic world. 1. Time. 2. Space. 3. Model of the world (centre, axis.) 4. Borderline. 5. Lands of the khan, bogatyr, female-bogatyr. 6. Nationals. 7. Khan palace. 8. Feast (meeting) in the palace.

II. Birth of the bogatyr.1.Appearing of the main hero (bogatyr). 2. Loneliness, orphanage. 3. Rapid growth. 4. First deeds (Alshee games, intrusion into the khan stavka etc.). 5. Bogatyr's appearance. 6. Physical qualities. 7. Wonderful skills. 
III. Bogatyr's horse. 1. Description of the horse appearance. 2. Physical abilities of the horse. 3. Unusual qualities of the horse. 4. Preparation for the expedition. 5. Saddling a horse. 6. Horse's running. 7. Help to the host.

IV. Hitting the road. 1. Bogatyr's choice. 2. Bogatyr's praise. 3. Dressing. 4. Munitions. 5. Blessing, message.

V. Bogatyr fight, battle. 1. Time, place and conditions of the fight, battle. 2. Ability to use different types of weapon (sword, axe, spade, bow). 3. Combat. 4. Bogatyr's state (emotional, psychological, physical). 5. State of nature. 6. Vital force of bogatyr. 7. Oath, battle cry. 8. Victory. 9. Praise of the winner. 10. Regrets of the defeated rival. 11. Killing of the rival. 12. Resurrection.

VI. Antagonists. 1. Appearance. 2. Supernatural skills. 3. Physical abilities. 4. Moral qualities (cunning, betrayal etc.).

VII. Bogatyr's marriage. 1. Message of the betrothed. 2. Hitting the road. 3. Testing (three types of men's competitions, difficult task etc.). 4. Help, advice, horse's reminding. 5. Coming back with the fiancée and her dowry. 6 . Feast in the palace.

VIII. Betrothed 1. Appearance. 2. Wonderful skills. 3. Moral and aesthetic advantages. 4. Intellectual skills. 5. Bogatyr qualities.

IX. Bogatyr feast. 1. Feast participants. 2. Duration of the feast. 3. Actions during the feast. 4. End.

X. Popular characters. 1. Shamans. 2. Sorceresses 3. Representatives of the Buddhist pantheon. 4. Spirits. 5. Totems. 6. Zaiachi.

XI. Fauna. 1. Animals. 2. Birds. 3. Fish. 4. Insects.

XII. World of objects. 1. Wonderful objects. 2. Weapon. 3. Objects of the material world. 4. Decorations. 5. Popular attributes. 6. Musical instruments.

The numbering can be open in order to make additions into the list of the ethnopoetical constants with other stable segments, if they are the bearers of the main information about the depicted event, image, phenomenon, action, object etc. The source text will be accompanied by the Russian translation.

Supporting (key) words, which form the "bunches" - constant symbolic combinations - the constants in the source and translated texts are italicized (baatr, bogatyr) and included into the "Glossary" section. Non-equivalent Lexis in translation also will be italicized in the translated text and additionally marked with the asterisk (unin*, terme*). This Lexis also will be presented in the "Glossary" section.

In brackets after the original text there will be mentioned the source, year of edition, volume (if any) and page (Dzhangar 1978: 1, 305). In case of the field material usage the data of the time and place of recording and the full name of the informant will be mentioned in brackets (RK, p. Orgakhin, 1980: Badmaev B. M.). Refer to the "List of the used texts" section to get more detailed information about the sources.

Further all the text material of the "Fond" in placed in alphabetic order (Buryat, Kalmyck, Mongol, Xinjiang). This seems to be logical and optimal, but not the only one possible variant.

Thus, the creation of the fond which combines poetic segments that are characterised by the stableness of the forms, constancy and frequency of usage in different genres of the Mongol nations' folklore (in epic, fairy tales, songs, ceremonial poetry), allows to characterise the fundamental constants for the folklore consciousness of the Mongol nations and reveal the ratio of the general Mongol, the regional and the ethno-local in the revealed fond.

(The article is prepared under the grant of the Russian Scientific Fund for the Humanities, project \# 14-24-03004)

\section{References}

Gatsak V. M., 2000. Folklore - the memory of tradition (Levels and forms of the ethnopoetic constancy). Dagestan Scientific Centre of the Russian Academy of Science, 8.

Parry M.L., 1930. Studies in the Epic Technique of Oral Verse-Making. I: Homer and Homeric Style. Harvard Studies in Classical Philology. vol. 41, pp: 80.

Lord A.B., 1960. The Singer of Tales. Harvard University Press. Cambridge (Mass.), pp: 35-36.

Lord A. B., 1956. Avdo Medjedovie. Guslar. Journal of American Folklore, 69: 323-324.

Foley J.M., 1981. The Oral Theory in Context. Oral Traditional Literature. Columbus, pp: 60-79.

Habunova E. Je., 2006. "Heroic epic "Dzhangar": poetic constants of the bogatyr life cycle. Comparative study of the national versions". Rostov-on-Don: Publishing house SKNC VSh., pp: 253.

Neklyudov S. Yu., 1984. About some aspects of folklore motives investigation. Folklore and ethnography. Leningrad, pp: $221-229$.

Kuzmina E. N., 2005. Guide for the typical places of the heroic epic of Siberian nations (Altaians, Buryats, Tuvinian, Khakases, Shors ,Yakuts). Experimental edition. Novosibirsk: Publishing house SO RAN,pp: 3 - 10.

Dzhangar. Kalmyck heroic epic. Texts of 25 songs. In 2 Volumes. 1978. Moscow, Volume I -pp: 441, Volume II - pp: 414. 